\title{
A PAISAGEM DE VILA VELHA E SEU SIGNIFICADO PARA A TEORIA DOS REFÚGIOS E A EVOLUÇÃO DO DOMÍNIO MORFOCLIMÁTICO DOS PLANALTOS DAS ARAUCÁRIAS
}

\author{
The Landscape of Vila Velha, its meaning for the Ice Age \\ Forests Refuge and the evolution of the Southern Brazilian \\ Araucaria highlands
}

Pedro Augusto Hauck da SILVA ${ }^{1}$

Everton PASSOS ${ }^{2}$

\begin{abstract}
RESUMO
Este trabalho visa reconstruir a paisagem durante o Pleistoceno Terminal da área do Parque Estadual de Vila Velha, uma das mais importantes unidades de conservação do Paraná, que preserva atualmente um mostruário de ecossistemas típicos dos planaltos meridionais, seja de campos, quanto de florestas subtropicais, assim como também diversos indivíduos pertencentes geneticamente ao domínio dos cerrados. Muito mais do que diagnosticar e classificar o tipo de paisagem existente no presente e no passado na região de Vila Velha, a pesquisa se esforça em contribuir com os conhecimentos sobre a evolução do Domínio Morfoclimático dos Planaltos das Araucárias, analisado dados paleopalinológicos e propondo hipóteses sobre as origens das paisagens dos planaltos do Sul do Brasil.
\end{abstract}

Palavras-chave: Evolução da paisagem; Teoria dos Refúgios; Vila Velha; Domínio dos Planaltos das Araucárias.

\begin{abstract}
This paper aims at reconstructing the late-pleistocene landscape of Vila Velha Park, one of the most important conservation areas of Paraná State, which preserves a typical ecosystem sample of the southern brazilian highlands. It consists of grasslands and subtropical forests as well as vegetal species considered palaeoclimate relicts of the driest pleistocenic epochs and that genetically descend from the central Brazilian Cerrado. More than an attempt to distinguish and classify Vila Velha's present and past types of landscape, the research tries to contribute to the knowledge regarding the evolution of the Araucaria Highlands Morphoclimatic Area. The methodology consists of analyzing palaeopalinologic data and proposing hypothesis concerning the origins of Southern Brazilian Highlands landscape.
\end{abstract}

Keywords: Landscape evolution; Ice Age Forest Refuges Theory; Vila Velha; Araucarias Highlands.

1 Geógrafo e Mestre em Geografia (DGEOG-UFPR). E-mail: pedro@gentedemontanha.com

2 Geógrafo, professor doutor do Departamento de Geografia - UFPR. E-mail: everton@ufpr.br 
SILVA, P. A. H.; PASSOS, E. A paisagem de Vila Velha e seu significado...

\section{INTRODUÇÃO}

O Parque Estadual de Vila Velha (P.E.V.V.), situado no município de Ponta Grossa, no Segundo Planalto do Paraná, está contextualizado pelas paisagens dos Campos Gerais, onde fácies de campos abertos se transacionam bruscamente com as florestas subtropicais típicas do Domínio Morfoclimático dos Planaltos das Araucárias, conforme classificação proposta por Ab'Sáber (2003), fisionomias de paisagem em total oposição na escala sucessional.

A notável diferença entre as fácies fitogeográficas do domínio das Araucárias é objeto de estudo desde épocas dos geógrafos viajantes e esta diferenciação já foi sentida por Saint Hilaire no século XIX (PEREIRA; IEGELSKI, 2002), mas foi somente com Maack (AB'SÁBER, 1981a), que a vegetação do sul do Brasil foi estudada com um viés evolucionista e daí surgiram as primeiras hipóteses sobre as origens da paisagem fitogeográfica dos planaltos sulinos.

Maack concentrou seus esforços no Estado do Paraná e em 1950 publicou o mais importante documento cartográfico sobre a vegetação no Estado, o Mapa Fitogeográfico do Paraná na escala 1:750.000. Tal documento é o mais importante registro da vegetação natural do Paraná, tendo em vista que seu autor viajou por todo o Estado antes da substituição da vegetação original pela agricultura e pastagem que destruiu a originalidade das paisagens.

Além de testemunhar as alterações da natureza no Estado, Maack foi capaz de teorizar, pela primeira vez, as origens da vegetação original do domínio das Araucárias, atribuindo às alterações climáticas do Quaternário um papel de suma importância para explicar a total oposição das fácies de paisagens florestais e abertas (MAACK, 1981, p. 200):

Estas associações florísticas naturais, existentes até há poucos decênios, desenvolveram-se somente a partir do Pleistoceno. Dos estudos geológicos dos depósitos quaternários antigos e dos perfis de solos, conclui-se que a mata se alastrou sobre os solos semi-áridos de estepes, partindo dos vales dos rios, de suas cabeceiras e dos declives das escarpas. Assim, as estepes de gramíneas baixas e de arbustos constituíram a cobertura primária e mais antiga do Paraná, sendo a mata a formação secundária mais recente. Numa época ainda indeterminada do Quaternário antigo, com o término da glaciação nas latitudes altas e médias, o clima predominante de estepes periodicamente seco foi substituído por um período pluvial com clima constantemente úmido e precipitações distribuídas por todos os meses do ano.
Maack ainda tece observações sobre o avanço de florestas sobre os campos nos anos de 1930, contribuindo com a hipótese de que as paisagens meridionais do Brasil ainda não haviam atingido um estágio de clímax, estando ainda em evolução antes da alteração humana.

Em 1930, ainda era possível observar o avanço das matas a partir de isolados capões de cabeceiras nas regiões, onde o equilíbrio natural não foi perturbado pela queima de roças ou queima regular dos campos. Este fenômeno ocorria principalmente na zona limítrofe da mata com os Campos Gerais (MAACK, 1981, p.200).

Além das fácies típicas do Domínio Morfoclimático dos Planaltos das Araucárias, o P.E.V.V. abriga também um excepcional mostruário de topografias ruiniformes (MELO et. al., 2002) que são heranças de processos geológicos e geomorfológicos que se enquadram na categoria de uma Paisagem de Exceção. "Fatos isolados, de diferentes aspectos físicos ecológicos inseridos no corpo geral das paisagens habituais". (AB'SÁBER 2003, p. 149),

As feições do relevo local no P.E.V.V. são remetentes a processos morfogenéticos, originados em ambientes ditos resistásicos e reafeiçoados por processos pedogenéticos de ambientes biostáticos. Há uma notável sucessão de processos na gênese geomorfológica regional que é responsável pela excepcionalidade e bizarrice das formas tomadas pelos arenitos, tal como a da "taça", o maior símbolo do P.E.V.V., que devido à peculiaridade da forma, foi durante muito tempo sendo atribuída como resultante do desgaste eólico, mas que de acordo com Melo et al. (2002) ela é decorrente de uma combinação de fatores, como variação faciológica do arenito, presença de estruturas rúpteis e ação de águas pluviais.

O sítio de Vila Velha, devido esta excepcionalidade paisagística, tem a presença de elementos na paisagem que são anômalos ao domínio das Araucárias e que são considerados como relictos, de acordo com Ab'Sáber (2003, p. 145), "espécies vegetais encontrada em uma localidade específica e circundada por vários trechos de outro ecossistema".

Em Vila Velha há pelo menos 175 espécies vegetais que ocorrem com grande tipicidade no interior do domínio dos cerrados (RITTER, 2008), sendo a área com maior concentração de espécies de cerrado dos Campos Gerais, mais do que a região do Parque Estadual do Cerrado em Jaguariaíva/PR, no entanto, sem 
apresentar uma fitofisionomia de cerrado, ou seja, estes elementos estão muito dispersos nas diversas fácies de paisagem do P.E.V.V., seja nos campos, quanto na borda dos capões de Araucária.

\section{A TEORIA DOS REFÚGIOS, SUBSÍDIOS PARA A COMPREENSÃO DA EVOLUÇÃO DA PAISAGEM DE VILA VELHA}

A documentação paleontológica, paleobotânica, palinológica e a interpretação de indicadores ambientais evidenciam que nem sempre, no decorrer do Quaternário, os domínios de natureza tiveram as mesmas feições geobotânicas e a mesma distribuição do que aquela apresentada ao início da colonização portuguesa no Brasil.

Tais evidências foram estudadas na década de 1960 e 1970 e a reunião dos conhecimentos acumulados destes estudos gerou subsídios importantes para a formulação da Teoria dos Refúgios Florestais, que trata da retração e expansão da cobertura vegetal dos domínios morfoclimáticos, formando antigos refúgios de flora e fauna e os atuais redutos. Estes estudos foram levados à cabo principalmente por Ab'Sáber, Haffer, Prance e Vanzolini (AB'SÁBER, 1992; HAFFER; PRANCE, 2002, VANZOLINI, 1992; VIADANA, 2000).

Haffer e Prance (2002) sugerem que a teoria se aplica à diferenciação biótica que ocorreu durante todo o Cenozoico e não somente durante o último máximo glacial. De acordo com Haffer e Prance (2002, p. 186):

\footnotetext{
A Teoria dos Refúgios propõe que as mudanças na vegetação seguiram reversões climáticas em virtude dos ciclos Milankovic durante algum período da História da Terra, causando a fragmentação dos centros de origem das espécies e o isolamento de uma parte das respectivas biotas em refúgios ecológicos separados entre si, onde populações de espécies (1) se extinguiram, (2) sobreviveram sem alteração, ou (3) se diferenciaramse em nível de espécie e subespécie.
}

Entretanto foi com a experiência adquirida nos estudos paleoambientais do último máximo glacial (U.M.G.) que a Teoria encontrou mais dados preservados para sua formulação. Estes dados mostram que durante o U.M.G., houve uma redução da temperatura média do planeta e como consequência, os polos confinaram mais água sob a forma de gelo, resultando na redução do nível médio dos mares, deixando expostas grandes faixas de terras antes ocupadas pela água do mar (VIADANA, 2000).

Em decorrência destas mudanças climáticas em nível mundial, as correntes marítimas frias ficaram mais intensas. A corrente das Malvinas chegaria até o litoral Sul do atual Estado da Bahia. Toda a faixa litorânea do Brasil Sul e Sudeste passou a ter influência direta desta corrente marítima e essas faixas de terra, dentre as quais a atual plataforma marinha que então aflorava, se tornaram espaços com climas mais secos (VIADANA, 2000).

As mudanças ambientais mais sentidas durante o U.M.G. foram relativas ao regime de chuvas, com regiões que tenderam para climas semiáridos e áridos e outros para climas sazonais, onde há um período de seis meses de chuvas e outro com seis meses de secas.

Durante este período, a cobertura vegetal higrófita sofreu um grande impacto com a perda de sua capacidade competitiva com as plantas xerófitas. Assim, a vegetação dos domínios de paisagem biostáticos, usando a nomenclatura de Erhardt (1966), sofreu uma drástica retração de sua atuação territorial, enquanto que a cobertura vegetal de domínios resistásicos, favorecida ecologicamente, avançou tomando novo arranjo espacial (AB'SÁBER, 1977a).

Mesmo com considerável avanço das floras xerófitas em decorrência da aridificação e semiaridificação geral no continente, as floras higrófitas não foram extintas, pois a biota úmida das paisagens pleistocênicas ficou retraída em áreas exíguas onde mesmo durante o período máximo de aridez houve a manutenção da umidade e pluviosidade, isso graças às características morfológicas dos domínios de paisagens que comportaram refúgios de flora e fauna. De acordo com Ab'Sáber (1992, p. 31):

\footnotetext{
Considera como um refúgio pleistocênico - no sentido do conceito original dos fundadores da teoria - como sendo o setor espacial de máxima retração em áreas das florestas preexistentes, com refugiação de faunas de sombra, devido à semi-aridificação dos espaços do entorno.
}

Existem até hoje muitos indícios morfológicos dos climas secos quaternários. Eles tiveram uma atuação no tempo menor do que os paleoclimas do Terciário que resultaram no vasto aplainamento que deu origem a algumas das grandes províncias geomorfológicas atuais do relevo brasileiro. No entanto, os paleoclimas quaternários, por mais que tenham atuado em uma escala de 
tempo geológica muito menor, deixaram sua impressão na paisagem seja em características ecológicas como edáficas (BIGARELLA et. al, 2003).

Nas características edáficas, a herança mais significativa deixada por esse paleoclima mais seco que atuou ao fim do Pleistoceno são as chamadas "Stone lines", ou simplesmente "linhas de pedra" (AB'SÁBER, 1959, 1966).

As linhas de pedra são horizontes de seixos sub-superficiais enterrados por colúvios posteriormente pedogeneizados, de 0,50 a 2,00 metros de profundidade. Tais seixos apresentam formas arestadas e angulosas, situam-se em extensas áreas das encostas dos morros e colinas de terras úmidas recobertas por florestas e campos no Sul e Sudeste brasileiro

Estas linhas de seixos horizontais seriam, de acordo com Bigarella (1964) e Ab'Sáber (1966), indícios de pedimentação em resposta à morfogênese na fase de semiaridez que ocorreu ao final do Pleistoceno. Tal hipótese afirma que em virtude do clima, a vegetação que recobre e protege o solo de agentes erosivos sofreu um fenecimento e por isso o material regolítico exposto sofreu transporte coluvial sendo então depositado em

\section{DADOS PALEOPALINOLÓGICOS}

A equipe de Behling é responsável por mais de uma dezena de trabalhos paleopalinológicos nos Planaltos de Araucárias no Sul do Brasil, dentre eles, o mais próximo de Vila Velha é uma turfeira localizada no município de Tibagi, uma região típica dos Campos Gerais do Paraná.

O perfil, partindo dos horizontes mais profundos ao superficial, de acordo com Behling (1997b), foi dividido em três zonas apresentadas a seguir.

ZONA I: (185-137,5 CM, 12.480-9.660 A.P., 10 AMOSTRAS)

Esta zona foi caracterizada por presença abundante de grãos de pólen de espécies campestres (89$93 \%$ ), principalmente pertencentes à família Poaceae (55-63\%), seguidos pelas famílias Cyperaceae, Asteraceae, Apiaceae; outros táxons como Xyris, Eriocaulon/ Paepalanthus, Caryophyllaceae e Plantago turficola apresentaram menor frequência. Grãos de pólen de árvores que compõem as Florestas Ombrófilas Mistas foram pouco frequentes $(0,4-3,0 \%)$, incluindo Araucaria regiões de baixada, sendo que a pedogênese atual ainda não foi capaz de apagar todos os traços da morfogênese deste clima pretérito.

A teoria dos Refúgios Florestais foi alvo de diversas críticas por formularem hipóteses baseadas em indícios indiretos e também devido à complexidade das mudanças ambientais na bacia amazônica (BUSH; OLIVEIRA, 2006).

Entretanto, no Sul do Brasil, como já postulava Maack na década de 1930, a sucessão ecológica dos campos para as florestas de Araucária mereciam um enfoque nas questões paleoclimáticas do Quaternário. Esta história evolutiva se encaixa na lógica da Teoria dos Refúgios, faltavam apenas os dados diretos da substituição dos campos por florestas.

Com os dados paleopalinológicos da região dos Campos Gerais, Behling (1997b) pôde demonstrar de maneira direta quais eram os indivíduos vegetais que compunham as paisagens da região e mostrar como ela evoluiu desde a época do último máximo glaciar, dando subsídios para a compreensão da origem da paisagem dos Planaltos das Araucárias, mas gerando uma dúvida sobre qual seria a origem genética dos campos subtropicais.
(0-0,2\%), Podocarpous, Lithraeae/Schinus e Sebastiana commersonia (Branquilho), apenas Mimosa scabrella (Bracatinga) caracterizou-se mais ou menos frequente. Foram encontrados somente vestígios de espécies de floresta latifoliada tropical, como Alchornea (Moraceae/ Urticaceae), Myrtaceaes e Palmeiras (Arecaceae). A taxa de grãos de pólen de espécies aquáticas foi alta (9,3-16,0\%), representada por Myriophyllum, Hydrocotyle, Ludwigia e Echinodorus. Esporos de Pteridófitas (samambaias e samambaiaçus), como Dicksonia sellowiana e Cyathea foram raros ou inexistentes.

A análise palinológica da época evidencia que no período indicado, 12.480 a 9.660 anos antes do presente, portanto ao término do U.M.G., a paisagem da região do Segundo Planalto era dominada por campos abertos com zonas higrófilas nas baixadas.

Espécies arbóreas da Floresta Ombrófila Mista e da floresta latifoliada tropical permaneceram nos fundos de vales. Locais como o canyon do rio lapó certamente tiveram uma grande importância na manutenção desta flora, entretanto é possível que grandes conjuntos de florestas de Araucária estivessem muito distantes do Segundo Planalto, como nos vales dos grandes rios 
do Terceiro Planalto, hipótese aventada por Ab'Sáber (1971), como refúgio do Iguaçu. Outro refúgio, desta vez da vegetação tropical úmida, deve ter se formado nos vales que drenam para o atlântico (bacia do Ribeira). A presença de espécies aquáticas como Myriophyllum, Hydrocotyle e Echinodorus evidenciam que os rios que cortam os planaltos eram naquela época perenes, mas mais rasos e muito menos caudalosos.

Este quadro paisagístico sugere um clima frio com geadas severas, com temperaturas mínimas abaixo de $-10^{\circ} \mathrm{C}$, já que é muito possível que neste período final de glaciação a temperatura média era de 3 a $5^{\circ} \mathrm{C}$ mais fria que o atual (BEHLING, 1997b). A pouca ocorrência de grãos de pólen de Araucaria se deve à necessidade desta espécie arbórea de condições quase que permanentes de umidade, o que justifica a presença desta árvore somente nos vales dos Campos Gerais daquela época.

ZONA II: (137,5-72,5 CM, 9.660-2.850 A.P., 13 AMOSTRAS)

Grãos de pólen de espécies vegetais que compõem os campos ainda foram predominantes (73-93\%). $\mathrm{Na}$ metade desta zona do perfil, a porcentagem de Poaceae foi alta e de Cyperaceae, baixa. Eriocaulon/ Paepalanthus e Xyris foram mais frequentes e Baccharis, Apiaceae e Caryophyllaceae são ausentes ou menos frequentes que na zona antecedente. A taxa de grãos de pólen de árvores da Floresta Ombrófila Mista continua baixa $(<1 \%)$, enquanto que as espécies que compõem a floresta latifoliada tropical foram pouco mais abundantes (3-9\%), mas muito inferiores se comparados com a taxa da vegetação de campos (BEHLING, 1997b).

Porcentagem de Myrsine aumentou substancialmente (1-5\%), enquanto que a taxa de espécies aquáticas sofreu uma redução $(0,4-5,0 \%)$, principalmente por causa do forte decréscimo de grãos de pólen de Myriophyllum e Hydrocotycole. Esporos de pteridófitas eram raros ou ausentes nesta zona. Destaca-se a ocorrência de esporos de Sphagnum seguido para o aumento da presença de algas como o Botryococcus e Zygnema. Particulas de carvão começam a ficar mais frequentes.

Neste período que abrange o Holoceno Inferior e Médio, a região de estudo continuava ocupada por vegetação campestre, entretanto há uma mudança na composição dos campos. Várias espécies passaram a ser mais abundantes como Eriocaulon/Paepalanthus enquanto outras desapareceram (Apiaceae).

Espécies da Floresta Ombrófila Mista continua- vam raras ou ausentes, devido ao regime de chuvas, com uma estação seca prolongada, entretanto, estas características climáticas possibilitaram que outras espécies arbóreas, de florestas tropicais latifoliadas, de acordo com Behling (1997b), se tornassem mais abundantes, como a pioneira Myrsine (M. umbellata, $M$. coriacea, M. guianensis, M. lancifolia), espécies típicas de cerrado que, de acordo com Ritter (2008), ainda hoje são encontradas em alguns redutos de cerrado no Paraná.

O aumento da taxa de calor, seguido pelo decréscimo das geadas, e pela manutenção de condições mais secas que a atual, deu condição para que a flora arbórea e arbustiva de cerrado refugiada se expandisse sobre a estepe de gramíneas do Pleistoceno Terminal. A taxa de umidade, no entanto, começou a mudar neste período. A presença de Sphagnum na depressão da atual turfeira indica a presença periódica de um baixo lençol de água aflorando que acarretou, inclusive, no aparecimento de Botryococcus. ZONA III (72.5-47.5 CM, 2850-1530 A.P., 5
AMOSTRAS)

Táxons de vegetação campestre continuam sendo o grupo mais abundante nesta zona (75-79\%), entretanto menos abundante que na zona inferior (zona II), principalmente pelo decréscimo de Poaceae. Senecio sp (Astereaceae) apresentou nesta zona, sua maior frequência, enquanto grãos de pólen da Floresta Ombrófila Mista começam a ser relevantes (2,5-5,0\%), principalmente Araucaria angustifolia (1,2-3,5\%), registrando a expansão da floresta subtropical.

O grupo das espécies das florestas tropicais latifoliadas representa valores altos principalmente de grãos de pólen de Alchornea e Moraceae/Urticaceae, e de Myrsine (6\%), que continua alta. Pela primeira vez samambaias e xaxins (pteridófitas) foram mais frequentes e houve um incremento da presença de esporos de Sphagnum.

Tais registros evidenciam que a partir do Holoceno as Florestas Ombrófilas se expandem a partir dos refúgios e passam a ocupar os planaltos, passando a formar um mosaico junto com os campos que ainda abundavam. A mudança climática dá condição à vegetação tropical latifoliada de habitar os vales anteriormente ocupados pela vegetação florestal subtropical. $\mathrm{O}$ aumento da umidade deu fôlego às Araucárias e aos xaxins para se expandirem sobre os campos e a presença contínua de Sphagnum indica esta mudança no regime pluvial dos planaltos. Há um curioso aumento 
SILVA, P. A. H.; PASSOS, E. A paisagem de Vila Velha e seu significado...

de queimadas, atestado com a presença de carvão, provavelmente devido à maior presença de capões Araucária entremeados aos campos.

\section{ZONA IV (47.5-0 CM, 1530-44 A.P, 9 AMOSTRAS)}

A vegetação campestre predomina (67-72\%), entretanto não mais como antes, pois as espécies de Poaceae diminuíram substancialmente ao ponto que espécies da Floresta Ombrófila Mista, como a Araucaria angustifolia, aumentaram mais de $10 \%$. O grupo das espécies das florestas tropicais latifoliadas e de samambaias e xaxins continuam mais ou menos com a taxa que no período anterior. Baccharis e outras Asteraceaes aumentaram com a redução dos campos e o registro dos Sphagnum já sobre vigência do clima atual, sem uma estação seca definida.

\section{CONSIDERAÇÕES FINAIS}

As paisagens do período do último máximo glacial eram totalmente distintas das atuais nos planaltos do Sul do Brasil. Os registros palinológicos refletem um clima muito mais seco dificultando o desenvolvimento de uma grande população de Araucaria. Por outro lado, estes registros mostram que as temperaturas mais baixas e com frequentes geadas, limitaram a expansão da vegetação de cerrado arbóreo e de florestas, favorecendo a expansão de um tipo de vegetação campestre subtropical.

A interpretação dada por Maack $(1948,1981)$ sobre a ocorrência de campos no Paraná como uma vegetação relictual do clima mais seco do Pleistoceno é correta e foi comprovada pelos estudos paleopalinológicos de Behling (BEHLING, 1997a, 1997b, 1998, 2002), (BEHLING; LICHTE, 1997), (BEHLING; PILLAR, 2007), (BEHLING et al., 2004), (BEHLING et al., 2007). A grande questão que Maack não pôde responder foi a origem genética de tal vegetação campestre subtropical tão extensiva no Pleistoceno Terminal e primórdios do Holoceno que ocorre em forma de redutos em diversas áreas de solos rasos e clima frio nos planaltos sulinos.

Com a constatação realizada por Ritter (2008) de que nos Campos Gerais há pelo menos 587 espécies típicas de cerrado, é inegável a participação genética da flora desse domínio de paisagem na constituição dos campos subtropicais. Isso ocorreu porque na vegetação dos cerrados há uma grande ocorrência de espécies de características ecológicas pioneiras, muito oportunas e que rapidamente colonizaram o espaço deixado pela retração de fisionomias vegetais mais exigentes.

Estas espécies, que são as que compõem o substrato herbáceo e arbustivo das fácies abertas de cerrado, embora tenham como centro de origem genético um domínio tropical, ao colonizar terras mais frias, mostram que não têm como fatores limitantes as baixas temperaturas e nem mesmo as frequentes geadas e que são muito adaptadas à ambientes mais secos. Assim, enquanto perduraram as condições climáticas impostas pelo período glaciar, estas espécies não encontraram resistência e obtiveram grande sucesso na colonização dos espaços mais frios e mais secos dos Planaltos do Sul, e das terras mais altas do Sudeste.

Quando as condições climáticas começaram a mudar nos planaltos, com a retomada do calor no Holoceno, período denominado de Optimum climaticum por Ab'Sáber (1980), a flora sensu strictu de cerrado e também da floresta Semidecidual, refugiadas em sítios protegidos das geadas e de outros fatores climáticos limitantes para este tipo de vegetação, passaram a se expandir. Neste período compreendido pelo Holoceno Médio, as massas de ar tropicais continentais invadiam os planaltos sulinos e não permitiam a atuação mais incisiva das frentes polares, resultando em aumento de temperaturas, mas não de pluviosidade.

Com a redução das temperaturas a partir do Holoceno tardio, como atesta Bigarella (1964), cerca de 3.000 A.P., houve um acentuado aumento na umidade dos planaltos, com grande expansão da Floresta de Araucária, devido suas estratégias de dispersão muito oportunas, fazendo retrair outras formações florestais e abertas. Este fenômeno não foi limitado ao Sul, ocorrendo também no Sudeste do país que abrigava refúgios antigos de Araucárias em vales protegidos (BEHLING, 1997a; BEHLING, 1998; BEHLING, 2002; BEHLING; LICHTE, 1997; BEHLING et al., 2007).

Este fato permite fazer uma reavaliação da Teoria dos Refúgios Florestais no que tange o conhecimento sobre a expansão das Araucárias pelo Sudeste. Ao contrário do que propõe Ab'Sáber (1977b, p. 12), que as Araucárias "teriam sofrido uma expansão para o norte, sob forma de pontes, acompanhando as terras altas do Brasil Oriental", a expansão ao norte ocorreu ao longo dos vales dos rios sob forma de florestas galerias subtropicais adaptadas às condições mais frias do período, mas limitadas à formações de Florestas Ombrófilas Mistas Aluviais.

As Florestas de Araucária teriam transposto os interflúvios do Rio Paranapanema alcançando outras bacias paulistas. A partir destes ecossistemas lineares, 
SILVA, P. A. H.; PASSOS, E. A paisagem de Vila Velha e seu significado...

com um incremento das temperaturas no Holoceno Tardio, as Araucárias teriam se expandido para zonas mais altas do Sudeste a compor redutos de Floresta Ombrófila Montana em sítios anteriormente recobertos por campos, como atesta Behling (1997a) e Behling et. al. (2007).

Os dados paleoecológicos tratados neste trabalho também permitem realizar indagações sobre a questão da sucessão ecológica existente nas associações de Araucárias, que formam as Florestas Ombrófilas Mistas. As florestas de Araucária, apesar de apresentarem um avançado estágio de sucessão, não são, no entanto, a flora clímax do domínio dos planaltos meridionais. Este fato é observado tendo os diversos argumentos que seguem.

Levando em consideração uma escala de tempo fisiográfica, os três mil anos de favorecimento climático desta formação vegetacional não foram suficientes para que a flora do domínio dos planaltos meridionais alcançasse seu clímax ecológico, fato atestado pela presença de grandes áreas consideráveis de campos e pela substituição das $A$. angustifolia pelas Lauraceaes nos capões mais desenvolvidos da floresta subtropical (SOARES, 1972) e também pela não existência de Araucárias no contraforte oriental da Serra do Mar, no limite nordeste do domínio.

As condições climáticas da Serra do mar a partir de 800 metros de altitude (MAACK, 1981; RODERJAN, et al., 2002), dão total aporte à ocorrência da Floresta Ombrófila Mista, entretanto, a Floresta Ombrófila Densa Montana, comportando associações de indivíduos mais especializados, colonizam esta cota altimétrica, que do outro lado de dita barreira orográfica é colonizada por associações de Araucária.

Esta constatação nos permite realizar observações importantes sobre a ecologia e o caráter sucessional das florestas de Araucária, pois através dela, nota-se a importância da ecologia do fogo (SOARES, 1972) na dispersão e manutenção das $A$. angustifolia na paisagem, já que queimadas naturais não ocorrem no contraforte da Serra do Mar voltado para o oceano, devido às características de grande barreira orográfica e altos índices de pluviosidades desta cadeia montanhosa.

Estas constatações induzem à hipótese de que a constituição genética da biota do domínio dos planaltos das Araucárias seja uma das mais recentes macropaisagens, com a configuração dos mosaicos de ecossistemas integrados e reconhecidos como "core", dos tecidos geoecológicos tropicais e subtropicais da América do Sul.

Enquanto outras áreas nucleares de domínios de paisagem reconhecidas como mais antigas flutuaram pelos espaços de sua hinterlândia (AB'SÁBER, 1981b), na dependência de feições físicas das paisagens que dão suporte à sua sobrevivência e desenvolvimento durante o instável Pleistoceno, os elementos vivos que compõem os ecossistemas que integram os mosaicos de paisagem do domínio dos planaltos das Araucárias foram sendo selecionados e rearranjados como tais durante a última fase de grandes mudanças climáticas, constituindo suas características genéticas, ao que tudo indica, muito recentemente.

Disto resulta o fato de que, o estágio sucessional inicial de uma floresta de Araucária, seja composto por elementos típicos de cerrados: os campos. Enquanto que o estágio mais avançado seja composto por elementos da Floresta Atlântica: As Lauraceaes, que muito lentamente subiram as principais drenagens dos planaltos meridionais (como o vale do Ribeira) e foram ocupando seu lugar de destaque nas florestas mais antigas e estáveis, substituindo a Araucária (BEHLING, 1997a; SOARES, 1972). A Floresta Ombrófila Mista, como bem afirma Roderjan et al.(2002), apresenta uma taxa de endemismo relativamente pequena, $40 \%$. A própria $A$. angustifolia, que é o elemento mais abundante e marcante dessa formação florestal, que representa um estágio de sucessão intermediário, não teve sua origem genética remetente do período de formação do "core" do domínio (embora seja considerada endêmica), já que sua origem se remete ao mesozoico (BEHLING, 2000) e, portanto pode ser considerada um fóssil vivo, sendo que ela própria estava muito dispersa, mas também muito fragilizada, durante o período glaciar, fato atestado pela reconstituição paleopaisagística da região de Catas Altas - MG (BEHLING; LICHTE, 1997) durante o máximo glaciar que demonstrou que no Sudeste houve associações de Araucária conformando Florestas Ombrófilas Mistas Aluviais, mas que quase desapareceram durante o U.M.G.

A paisagem original do Paraná, descrita por Maack (1981), mostra que o processo sucessional das paisagens dos planaltos ainda estavam em evolução. Ao longo do Vale do Rio Iguaçu e Paraná fixou-se um grande refúgio de Florestas de Araucária durante o U.M.G. A maneira como Maack (1981) classificou a fitogeografia da região, como "Mata subtropical do Terceiro Planalto" atesta a história da retropicalização do Oeste do Paraná durante o Holoceno, quando espécies da Floresta Estacional (Lianas, Syagrus e Euterpe) invadiram a Floresta Ombrófila Mista (Araucaria), criando um cenário de competição em um estágio médio de evolução por sorte descrita antes de sua inteira destruição. Tal paisagem disclimax resultou na sugestão de uma importante 
SILVA, P. A. H.; PASSOS, E. A paisagem de Vila Velha e seu significado...

hipótese aventada por Ab'Sáber (1981b, p. 20):

Um antigo refúgio de matas subtropicais situado no Vale do Paraná (extremo Oeste do Paraná, que designamos provisoriamente de refúgio de Foz do Iguaçu) deve ter se tropicalizado nos últimos milênios, afogado que foi pelas florestas de climas quentes, reexpandidas a partir de refúgios situados no Norte do Paraná e Oeste de São Paulo.

Estes argumentos apoiados nas evidências descritas neste trabalho induzem na sugestão da hipótese da jovialidade do domínio dos planaltos das Araucárias. Os estudos paleogeográficos das paisagens de exceção do interior deste domínio de paisagem podem vir a confirmar ou refutar esta hipótese.

Para tanto, um ponto crucial no tratamento da história evolutiva do domínio morfoclimático dos planaltos das Araucárias é reconstruir o caminho da flora de cerrado que veio a constituir os campos subtropicais do Pleistoceno Terminal/Holoceno. Nesta tarefa, o estudo paleogeográfico das áreas consideradas como atuais redutos deste tipo de vegetação nos planaltos sulinos, merecem destaque, pois elas podem ser chaves para a reconstituição paleopaisagística dos planaltos em fases anteriores à do último máximo glacial.

A ocorrência, de acordo com Ritter (2008), de uma grande diversidade de indivíduos vegetais típicos de cerrado e ao mesmo tempo a ausência de fisionomias típicas deste domínio, nos permite concluir que Vila Velha comportou refúgios em longo prazo de cerrado antes do U.M.G. Hoje em estágio avançado de extinção, com a organização destes indivíduos somente na forma de relictos.

Tendo a certeza da senilidade do domínio dos cerrados (AB'SÁBER, 1981b) e sua atuação muito abrangente nos paleoespaços dos planaltos brasileiros, é possível que nos primórdios do Pleistoceno os planaltos que hoje estão em fase final de destruição em Vila Velha fossem, na época, recobertos por cerrado sensu strictu e cerrado campestres com um clima mais quente e úmido, responsável pela esculturação da maioria das formas bizarras do relevo.

Esta contraproposta é apoiada por Hafer e Prance (2002) que afirma ser possível expandir o modelo teórico-metodológico da Teoria dos Refugios para fases climáticas mais remotas do Quaternário. Nas palavras de Hafer e Prance (2002, p. 186):
Nós enfatizamos que a teoria não se restringe ao Pleistoceno, mas aplica-se também à diferenciação biótica durante o Cenozóico e, mais cedo (como durante o Quaternário, quando os ciclos de Milankovitch causaram oscilações no nível do mar, alterações rítmicas nas fácies de estratos geológicos e mudanças climático vegetacionais nos continentes.

Atento à esta questão da escala de tempo, Ab'Sáber (1981b, p. 30) justifica a pouca experiência da Teoria do Refúgios em época mais remotas:

\begin{abstract}
Do ponto de vista fitogeográfico a identificação das áreas nucleares dos antigos refúgios constitui-se em uma tarefa de grande dificuldade, notoriamente aproximativa [...] a recomposição da tropicalidade - nos últimos 12.800 anos - que por fim ocasionou suturas entre os antigos núcleos de refúgios, mascarando seus limites e dificultando sua cartografação aproximada.
\end{abstract}

A identificação de Vila Velha como antiga área refúgio de cerrados na atual região geoecológica dos Campos Gerais releva a importância preservacionista na área, justifica sua rica biodiversidade e obriga a condução de pesquisas multidisciplinares no tratamento desta questão paleogeográfica de grande importância para a Teoria dos Refúgios Florestais, nas palavras de Ab Sáber (1992, p. 30):

\begin{abstract}
Nesta perspectiva, os refúgios florestais pleistocênicos - para os quais foi elaborada a teoria - seriam os setores de mais demorada permanência de vegetação tropical e de seus acompanhantes faunísticos, ao máximo da grande retração das condições tropicais úmidas. Feita a proposta básica, tornou-se fácil alimentar-se ampliações conceituais, estendendo-se o conceito de refúgio a outros espaços geoecológicos, onde certamente ocorreram dinâmicas biogeográficas similares ou análogas.
\end{abstract}

A importância do sítio de Vila Velha para a Teoria dos Refúgios é que este atual reduto de cerrado, embora já mascarado por mudanças paleoambientais mais recentes e pelo clima atual, possa ser um renascente presente à longo prazo na paisagem de um cerrado primitivo que permaneceu em refúgio isolado por muito tempo, tendo por vezes seu "stock" genético renovado com as sucessivas mudanças climáticas dos ciclos de Milankovich. 
SILVA, P. A. H.; PASSOS, E. A paisagem de Vila Velha e seu significado...

Essa questão permite mudar a escala de tempo empregada até agora no tratamento da Teoria dos Refúgios para períodos anteriores ao último máximo glacial. Ampliando o limite de análise para o de uma idade geomorfológica e não meramente fitogeográfica. Esta seria a idade da elaboração dos macrocompartimentos do relevo do Brasil. Portanto, abrangendo a importância desta Teoria no tratamento de importantes eventos evolutivos das paisagens.

O estudo evolutivo integrado da paisagem de Vila Velha em longo prazo, como bem propõe a Teoria dos Refúgios, pode desvendar o enigma que se põe sobre a história do domínio dos planaltos das Araucárias. Este seria, no entanto, o significado da paleopaisagem de Vila Velha para as pesquisas do Quaternário.

\section{REFERÊNCIAS}

AB'SÁBER, A. N. Problemas Paleogeográficos do Brasil Sudeste. Boletim Geográfico, São Paulo, v. 12. 1959/1955. p. 394-405.

AB'SÁBER, A. N. Revisão dos conhecimentos sobre o horizonte subsuperficial de cascalhos inhumados do Brasil oriental. Noticia Geomorfológica, Campinas, a. VI, n. 11, p. 59-80, jun. 1966.

$A B$ 'SÁBER, A. N. A organização natural das paisagens inter e subtropicais brasileiras. In: SIMPÓSIO SOBRE O CERRADO. Edgard Blücher: Editora Alumbramento. n. 3. São Paulo. 1971. p. 1-14.

AB'SÁBER, A. N. Espaços ocupados pela expansão dos climas secos na América do Sul, por ocasião dos períodos glaciais quaternários. Paleoclimas, v. 3, São Paulo, 1977a.

AB'SÁBER, A. N. Topografias ruiniformes no Brasil: Notas prévias. Gemorfologia, n. 50. São Paulo: IG-USP. 1977b.

AB'SÁBER, A. N. Razões da retomada parcial de semi-aridês Holocênica, por ocasião do "Otimum Climaticum". InterFácies, São José do Rio Preto: IBILCE, n. 8, 1980.

AB'SÁBER, A. N. Reinhard Maack (1892-1969) e as Geociências do Paraná. In: MAACK, R; Geografia Física do Paraná. 2. ed. Rio de Janeiro: José Olympio, 1981a.

AB'SÁBER, A. N. Domínios morfoclimáticos atuais e quaternários na região dos cerrados. Craton \& Intracation: Escritos e Documentos. n. 14. UNESP-IBILCE. São José do Rio Preto: UNESP-IBILCE. 1981b.

$A B$ 'SÁBER, A. N. A teoria dos refúgios: Origem e significado. Revista do Instituto Florestal, Edição especial, São Paulo, março de 1992.

AB'SÁBER, A. N. Os domínios de natureza do Brasil: potencialidades paisagísticas. São Paulo: Ateliê Editorial, 2003. 159p.

BEHLING, H. Late Quaternary vegetation and fire history from the tropical mountain region of Morro do Itapeva, SE, Brazil. Paleogeography, Palaeoclimatology, Palaeoecology, n. 129. p. 407-422, 1997a.
BEHLING, H. Late Quaternary vegetation, climate and fire history of the Araucaria forest and campos region from Serra Campos Gerais, Paraná State (South Brazil). Review of Palaeobotany and Palinology, n. 97, p. 109-121, 1997b.

BEHLING, H. Late Quaternary vegetational and climatic changes in Brazil. Review of Palaeobotany and Palinology, n. 99, p. 143-156, 1998.

BEHLING, H. South and southeast Brazilian grassland during Late Quaternary times: a sythesis. Palaeogeography, Palaeclimatology, Palaeoecology, n. 177, p. 19-27, 2002.

BEHLING, H; LICHTE, M. Evidence of dry and cold Climatic Conditons at Glacial Times in Tropical Southeastern Brazil. Quaternary Research, n. 48, p. 248-358,1997.

BEHLING, H. Arakarienwälder Südbrasiliens im Spätquartär. Natur und Museum, Frankfurt, v. 5, n. 130, p. 155-161, 2000.

BEHLING, H; PILLAR, V. D. P; Late Quaternary vegetation, biodiversity and fire dinamics on the southern Brazilian highland and their implication for conservation and management of modern Araucaria forest and grassland ecosystems. Philosophical transactions of the royal society, n. 362, p. 243-251, 2007.

BEHLING, H; PILLAR, V. D; ORLÓCI, L; BAUERMANN, S. G; Late Quaternary Araucaria Forest, grassland (Campos), fire and climate dynamics, studied by high resolution pollen, charcoal and multivariate analyses of the Cambará do Sul core in southern Brazil. Palaeogeography, Palaeclimatology, Palaeoecology, n. 203, p. 277-297, 2004.

BEHLING, H; DUPONT, L; SAFFORD, H. D; WEFER, G; Late Quaternary vegetarion and climate dynamics in the Serra da Bocaina, southeastern Brazil. Quaternary Internacional, n. 161, p. 22-31, 2007.

BIGARELLA, J. J. Variações climáticas no quaternário e suas implicações no revestimento florístico do Paraná. Boletim Paranaense de Geografia, Curitiba: UFPR, v.10, n. 5, 1964.

BIGARELLA, J. J. Variações climáticas no quaternário superior do Brasil e sua datação radiométrica pelo método do carbono 14. Paleoclimas, São Paulo: IG-USP, n. 1, 1971. 
SILVA, P. A. H.; PASSOS, E. A paisagem de Vila Velha e seu significado...

BIGARELLA, J. J.; ANDRADE LIMA; RIEHS, P. J.; Considerações a respeito das mudanças paleoambientais na distribuição de algumas espécies vegetais e animais no Brasil. Separatas dos Anais da Academia Brasileira de Ciências, v. 47. Curitiba- Porto Alegre, 1975. p. 411-464.

BIGARELLA. J. J.; PASSOS, E.; HERRMANN, M. L. P.; SANTOS, G. F.; MENDONÇA, M.; SALAMUNI, E.; SUGUIO, $\mathrm{K}$. Estrutura e origem das paisagens tropicais e subtropicais. v. 3. Florianópolis: Editora da UFSC, 2003. 552p.

BUSH, M. B.; OLIVEIRA, P. E. The rise and fall of the Refugial Hypothesis of Amazonian speciation: a paleoecological perspective. Biota Neotrop. Campinas, v. 6, n. 1, 2006. Disponível em: <http://www.scielo.br/scielo.php?script=sci_a arttext\&pid=S167606032006000100002\&Ing=en\&nrm=isoo>. Accesso em: 26/9/2009.

ERHART, H. A Teoria Bio-resistásica e os problemas biogeográficos e paleobiológicos. Noticia Geomorfológica, Campinas, n. 11, p. 51-58, jun. 1966.

HAFFER, J.; PRANCE, G. T. Impulsos climáticos da evolução na Amazônia durante o Cenozóico: sobre a teoria dos Refúgios da diferenciação biótica. Estudos Avançados, v.16, n.46, p.175-206, set./dez. 2002.

HAUCK, P; Cerrados, campos e Araucarias: A teoria dos Refúgios Florestais e o significado paleogeográfico da paisagem do Parque Estadual de Vila Velha, Ponta Grossa Paraná. 160 f. Dissertação (Mestrado) - Universidade Federal do Paraná. Curitiba, 2009.

MAACK, R. Geografia Física do Estado do Paraná. 2. ed. Rio de Janeiro: Joaquim Olympio, 1981.

MAACK, R. Notas preliminares sobre clima, solos e vegetação do Estado do Paraná. Arquivos de Biologia e Tecnologia, Curitiba, v. 2, p.102-200, 1948.

MELO, M. S.; BOSETTI, E. P.; GODOY, L. C.; PILATTI, F; Vila Velha, PR: impressionante relevo ruiniforme. In: SCHOBBENHAUS, C.; CAMPOS, D. A.; QUEIROZ, E. T.; WINGE, M.; BERBERT-BORN, M. (Eds.). Sítios geológicos e paleontológicos do Brasil. Brasília: DNPM-CPRMSIGEP, 2002. p. 269-277.

PEREIRA, M. A. M.; IEGELSKI, F. O paraíso terrestre no Brasil: Os campos gerais do Paraná no relato de August Saint Hilaire. Revista de História Regional. Ponta Grossa, p. 47-72, 2002. Disponível em: <http://www.revistas.uepg.br/index.php?journ al=rhr\&page=article \&op=viewFile \&path $\% 5 B \% 5 D=93 \&$ path $\%$ 5B\%5D=126>. Acesso em: 04/01/2009.

RITTER, L. M. O. Composição florística e aspectos físicos do cerrado nos Campos Gerais, Paraná. Dissertação (Mestrado) - Universidade Estadual de Ponta Grossa - UEPG, Ponta Grossa, 2008.

RODERJAN, C. V.; GALVÃO, F.; KUNIYOSHI, Y. S.; HATSCHBACH, G. G. As unidades fitogeográficas do estado do Paraná. Ciência\&Ambiente, Santa Maria: Universidade Federal de Santa Maria, n. 24, p. 75-92, 2002.

SOARES, R. V.; Considerações sobre a regeneração natural da Araucaria angustifólia. Revista Floresta, Curitiba, v. 10, n. 2. 1972.

VANZOLINI, P. E. Paleoclimas e especiação em animais da América do Sul Tropical. Estudos Avançados, São Paulo, v. 6, n. 15. 1992.

VIADANA, A. G. A teoria dos refúgios florestais aplicada ao estado de São Paulo. 166 p. Tese (Livre Docência) - Instituto de Geociências e Ciências Exatas, Unesp, Rio Claro, 2000. 


\section{RA’E GA: O ESPAÇO GEOGRÁFICO EM ANÁLISE}

ISSN $2177-2738$

\section{DIRETRIZES PARA O AUTOR}

A revista $R A^{\prime} E$ GA - O Espaço Geográfico em Análise é um veículo de publicação do Departamento de Geografia e Programa de Pós-graduação em Geografia da Universidade Federal do Paraná, sendo que ela recebe contribuições científicas na forma de texto relacionadas à ciência geográfica e áreas afins. Os artigos são submetidos à apreciação do Conselho Editorial da Revista, que acata ou não a publicação. Essa decisão será comunicada aos autores via e-mail, sem compromisso de devolução dos originais.

\section{I - Orientação geral}

1. O original deverá ser submetido ao sistema eletrônico de revistas: SER (www.ser.ufpr.br/raega), além de uma cópia em CD-R a ser enviada para o Editor Científico para fins de arquivo (depois de submetida ao sistema SER).

2. Os artigos devem ter de 10 a 30 páginas digitadas, incluindo figuras, tabelas e referências. Em casos especiais, a serem avaliados pelos editores, serão aceitos originais com número superior de páginas.

3. Os artigos serão preferencialmente escritos em português ou espanhol.

\section{II - Formato do texto}

1. Os textos dos trabalhos devem ser digitados em computadores tipo IBM-PC utilizando-se o programa MICROSOFT WORD FOR WINDOWS. Os textos devem ser digitados em letra Arial, corpo 12, com indicação de parágrafo, espaçamento 1,5, respeitando as normas da ABNT .

2. As figuras devem ser enviadas em formato digital BMP,.TIFF (não comprimido) ou .JPG e, no caso de tabelas e gráficos, devem ser feitos com o MICROSOFT WORD FOR WINDOWS ou MICROSOFT EXCEL, devidamente acompanhados de cópia em papel, e respeitando as medidas máximas de $21 \mathrm{x}$ $27,5 \mathrm{~cm}$. O texto deve indicar o local das figuras e tabelas.

3. As figuras serão publicadas preferencialmente em preto e branco. Se houver necessidade das figuras serem publicadas coloridas, o custo ficará a cargo do autor. Nesse caso deve ser consultado o editor.

4. Figuras e tabelas devem apresentar título e legendas em português ou espanhol.

\section{III - Organização dos textos}

Na primeira folha deverá constar o título (português e inglês), nome(s) do(s) autor(es), vínculo institucional e titulação. Na segunda página deverá constar o resumo (inglês e português) em um único parágrafo que contenha entre 5 e 10 linhas e palavras-chave (no máximo cinco palavras).

\section{IV - Referências e citações}

De acordo com a NBR-10520:2001 da ABNT, as referências deverão ter chamadas no texto pelo(s) sobrenome(s) do(s) autor(es), em maiúsculas, com data e paginação, quando dentro de parêntesis: (SANTOS, 1995, p.90) e apenas com a primeira letra em caixa alta, com as outras em caixa baixa, quando inseridas na frase: Segundo Santos (1995, p.8). Caso um mesmo autor citado tiver mais de uma publicação no mesmo ano, identificar cada uma delas por letras, (SANTOS, 1995a, p.6). Somente as referências citadas no texto deverão constar ao final do texto, em ordem alfabética, e elaborada de acordo com a NBR-6023:2000 da ABNT. 


\section{Livros}

SOBRENOME, Nomes. Título do livro. Local de Edição: Editora, data.

\section{Partes de livros}

SOBRENOME, Nomes (do autor do capítulo). Título do capítulo. In: SOBRENOME, Nomes (Ed., Org., Comp.) Título do livro. Local de Edição: Editora, ano. Número do Capítulo, p. página inicial - página final do capítulo.

\section{Artigos de periódicos}

SOBRENOME, Nomes. Título do artigo. Título do Periódico, Local de publicação, número do volume, número do fascículo, p. página inicial - página final, ano.

\section{Trabalhos acadêmicos}

SOBRENOME, Nomes. Título do trabalho acadêmico. f. Tese/Dissertação/Monografia (Doutorado/Mestrado/ em ...) - Setor, Universidade, local da defesa, data de defesa.

\section{Trabalhos em eventos}

SOBRENOME, Nomes. Título do trabalho. In: NOME DO EVENTO EM CAIXA ALTA, número do evento, ano de realização, local. Título...(Anais, Atas, Proceedings e etc.). Local de publicação: Editora, data, página inicial-final.

\section{Artigos de periódicos online}

SOBRENOME, Nomes. Título do trabalho. Fonte. Disponível em: <endereço eletrônico>. Acesso em: data (dia/mês/ano).

As citações textuais de até três linhas deverão aparecer no decorrer do texto, na mesma letra e entre aspas. As citações de mais de três linhas deverão ser digitadas com recuo, sem aspas nem itálicos e em letra de tamanho menor do que aquela do texto principal. Em ambas as citações deve ser referido o SOBRENOME do autor, ano, página.

RA'E GA: O Espaço Geográfico em Análise

Av. Cel. Francisco H. dos Santos, 100 - Jardim das Américas - Centro Politécnico

CEP 81532980 - Caixa Postal 19001 - Curitiba - PR

Fone: (41) 3361-3454 - Fax (41) 3361-3244

e-mail: raega@ufpr.br - web site: www.geografia.ufpr.br/raega 


\section{RA’E GA: O ESPAÇO GEOGRÁFICO EM ANÁLISE}

ISSN $2177-2738$

\section{INSTRUCTIONS TO AUTHORS}

The RA'E GA - O Espaço Geográfico em Análise journal, published by the Department of Geography and the Post-Graduate Studies Program in Geography - Master's and Doctorate's Level of the Federal University of Paraná, receives scientific contributions related to the geographic science and related areas. Articles may be published once approved by the Editorial board. Authors who submitted papers will receive the Editorial board's decisions by e-mail. Originals of submitted papers may not be returned to authors.

\section{I - General rules}

1. Originals should be sent to SER (Electronic Journal System) at the following address: <www.ser.ufpr.br/ raega>. After that, a CD-R copy must be sent to the Editor to be part of our filing system.

2. Papers should not be longer than 30 pages and not shorter than 10 pages, including fi gures, tables and references. In some special cases, which will be analyzed by the Editor, longer originals may be submitted.

3. Papers should be written either in Portuguese or in Spanish.

\section{II - Text format}

1. Papers should be typed in IBM-PC computers; MICROSOFT WORD FOR WINDOWS program should be used. They also should be typed in Arial letters, size 12, 1.5 spaced lines indenting first lines of paragraphs; ABNT rules should be followed.

2. Figures should be sent in BMP, .TIFF (not compressed) or .JPG digital format. Tables and graphics should be done by means of MICROSOFT WORD FOR WINDOWS or MICROSOFT EXCEL. Figures, tables and graphics should be sent printed, and they should not exceed $21 \times 27,5 \mathrm{~cm}$. Texts should indicate the appropriate place for figures and tables.

3. Figures should be published in black and white. Authors should agree to pay for additional costs in case of colored figures; these cases will be analyzed by the Editor.

4. Figures and tables should have titles and subtitles either in Portuguese or Spanish.

\section{III- Text organization}

The first page should contain: the title (both in Portuguese and in English), the author's names, Institution and titles. The second page should include an abstract (both in Portuguese and in English), in an only paragraph with 5 to 10 lines, and at most 5 (fi ve) key words.

\section{IV - References and citations}

According to NBR-10520:2001 from ABNT, the references should be called in the text by the author's surname in capital letters, date and page when in parenthesis (SANTOS, 1995, P. 90) and in small letters when within a sentence: According to Santos $(1995$, p. 8). If the same cited author has more than one publication in the same year, each one should be identified with letters, (SANTOS, 1995a, p. 6). Only the references that have been cited in the text should be mentioned in the reference list, in alphabetical order and created according to the NBR-6023:2000 from ABNT. 


\section{Books}

SURNAME, Names. Title. Place: Publisher name, date.

\section{Parts of books}

SURNAME, Names (chapter author). Chapter title. In: SURNAME, Names (Eds.; Org.). Book title. Place: Publisher name, year. Chapter number, chapter page number range (p. 10-18).

\section{Periodical articles}

SURNAME, Names. Article title. Journal Title. Place, volume number, issue number, p. page number range, year.

\section{Academic reports}

SURNAME, Names. Report title. Total page number. Thesis/Dissertation/Monograph (Doctory/ Mastery in ...) - School of ..., University, Place, date.

\section{Papers presented at meetings}

SURNAME, Names. Paper title. In: CONFERENCE NAME IN CAPITAL LETTERS, conference number, year, Place. Title... (Annals, Acts, Proceedings). Place: Publisher name, date, page number range.

\section{Online journal articles}

SURNAME, Names. Article title. Publisher. Journal Title. Place, volume number, issue number, p. page number range, year/date. Available at: <http://address>. Captured in: day/month/year.

Quotations of three lines or shorter should be showed in "quotation marks" and in the same font-size in the running text. Quotations of more than three lines should be indented at the left margin throughout, without any quotation marks or italics and in a smaller font than the main text. Both must be referred to as AUTHOR'S SURNAME, year, pages.

RA'E GA: O Espaço Geográfico em Análise

Av. Cel. Francisco H. dos Santos, 100 - Jardim das Américas - Centro Politécnico

Zip Code: 81532980 - P.O. Box: 19001 - Curitiba - PR

Phone number: (41) 3361-3454 - Fax number: (41) 3361-3244

e-mail: raega@ufpr.br - web site: www.geografia.ufpr.br/raega 


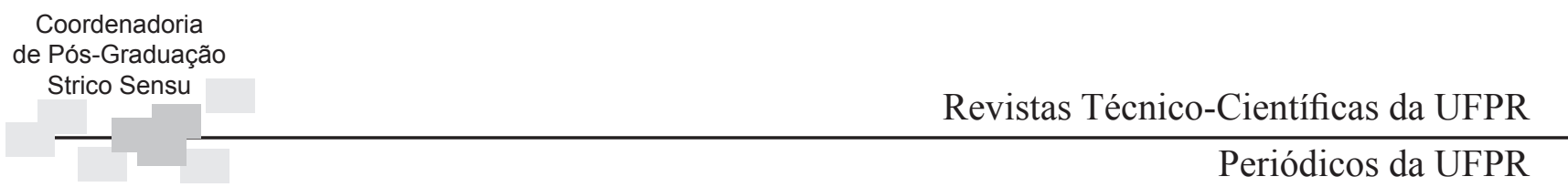

A Universidade Federal do Paraná instituiu o Sistema Eletrônico de Revistas (SER), abrindo um importante canal de interação entre usuários e a comunidade científica. Neste espaço estão listadas as Revistas Técnico-Científicas publicadas com recursos próprios ou com recursos do programa de apoio à publicação instituído pela UFPR.

O SER utiliza-se do Open Journal System, software livre e com protocolo internacional que permite a submissão de artigos e o acesso às revistas de qualquer parte do mundo. Nesse sistema já estão cadastradas 42 revistas da UFPR, abrangendo diversas áreas de conhecimento.

O sistema pode ser acessado por AUTORES, para a submissão de trabalhos, CONSULTORES, para a avaliação dos trabalhos, EDITORES, para o gerenciamento do processo editorial e USUÁRIOS, interessados em acessar e obter CÓPIAS de artigos já publicados nas revistas.

A SUBMISSÃO de artigos é feita por meio eletrônico e o autor poderá fazer o ACOMPANHAMENTO do processo de AVALIAÇÃO por parte dos consultores até a editoração final do artigo. As NORMAS de publicação e demais instruções, bem como os endereços dos editores são encontrados nas páginas de cada revista.

O trabalho de editoração de algumas revistas (Boletim Paranaense de Geociências, Desenvolvimento e Meio Ambiente, Educar em Revista, Extensão em Foco, História: Questões \& Debates, RA'E GA: O Espaço Geográfico em Análise, Revista de Economia e Revista Letras) é supervisionado pela EDITORA UFPR, que conta com corpo editorial especializado que se ocupa da revisão final dos volumes de seus respectivos periódicos, dentro dos padrões estabelecidos pela Editora. Findo o processo de editoração, uma cópia (pdf) dos artigos é disponibilizada em meio digital, dentro do Sistema SER, enquanto outra segue para impressão nas gráficas determinadas para cada publicação.

Para submeter um trabalho pela primeira vez será, antes, necessário entrar em CADASTRO. Uma vez cadastrado, abre-se uma caixa de diálogo indicando os passos a serem seguidos para o processo de submissão do artigo. Desejando apenas consultar trabalhos já publicados, basta acessar ARQUIVOS e obter o artigo desejado.

O SER oferece ainda o Public Knowledge Project, poderosa ferramenta de pesquisa, com acessibilidade global. Para fazer a busca por um tema de seu interesse utilizando essa ferramenta basta clicar em PKP e, em seguida, digitar uma palavra-chave na caixa de diálogo. Com isso você acessará artigos sobre o tema de seu interesse publicados em diversas partes do mundo.

Universidade Federal do Paraná

Pró-Reitoria de Pesquisa e Pós-Graduação (PRPPG)

R. Dr. Faivre, 405 - Ed. D. Pedro II, $1^{\circ}$ andar, Curitiba, Paraná, Brasil

CEP: 80060-140 - Telefone: (41) 3360-5227/ 3360-5335 - FAX: (41) 3360-5113

ser@ufpr.br

prppg@ufpr.br 